Ciência e Natura, Santa Maria, v. 37 n. 4 set-dez. 2015, p. 122-140

Revista do Centro de Ciências Naturais e Exatas - UFSM

ISSN impressa: 0100-8307 ISSN on-line: 2179-460X

\title{
METODOLOGIA PARA SELEÇÃO DE ÁREAS APTAS À INSTALAÇÃO DE ATERROS SANITÁRIOS CONSORCIADOS UTILIZANDO SIG
}

\author{
Methodology to select able areas for sanitary consorted landfill installation using GIS
}

\author{
Roberto Wagner Lourenço, Darllan Collins da Cunha e Silva, Jomil Costa Abreu Sales, Gerson \\ Araujo de Medeiros, Rafael Arosa Prol Otero
}

Universidade Estadual Paulista "Júlio de Mesquita Filho", UNESP, Sorocaba, SP, Brasil

\begin{abstract}
RESUMO
Um dos atuais problemas ambientais e financeiros, enfrentado pelas cidades está relacionado a disposição final e adequada dos resíduos sólidos urbanos em aterro sanitário. A escolha do local adequado está condicionada a diversos fatores como, a proximidade dos cursos d'água, resistência do solo aos efeitos contaminantes, proteção de áreas de preservação, tamanho da área disponível, distância entre a coleta e a disposição, ou seja, são questões que tornam os estudos sobre o tema relevantes. Neste contexto, utilizou-se uma metodologia para avaliar o potencial de seleção de áreas para implantação de aterro sanitário, considerando como área de estudo municípios consorciados e técnicas de Sistemas de Informações Geográficas. O método utilizado considerou como critérios para exclusão de áreas inaptas, as zonas de segurança aeroportuária, Unidades de Conservação e outros aspectos técnicos operacionais e ambientais que, ponderados segundo sua influência dentro do tema, geraram o ranqueamento de áreas mais indicadas para a instalação de um aterro sanitário com horizonte de operação de 20 anos. Desta forma, o estudo detectou que menos de 50\% da área estudada está apta a tal empreendimento, ranqueando 31 locais com maior aptidão à implantação de aterro sanitário segundo a análise multicriterial por sobreposição ponderada.
\end{abstract}

Palavras chaves: geoprocessamento, planejamento urbano, resíduos sólidos urbanos.

\begin{abstract}
Nowadays, one of the financial and environmental problems faced by cities is related to the adequate final disposal of solid waste in municipal sanitary landfills. The selection of the areas implies in several factors as the proximity of watercourses, soil resistance to contaminating effects, protection of conservation areas, size of the area available, distance between collection and disposal, which are the main issues that make the topic relevant. Thereby, was employed a methodology to assess the potential for selected of areas with the capacity to receive a landfill, considering as the study areas intercropping municipalities, by using techniques of Geographic Information Systems. The method used, considered as criteria of exclusion for unsuitable areas, the airport security zones, conservation unities and others operational and technical aspects of environmental, weighted according to their influence within the theme, generate the ranking of the most suitable areas for 20-years operation of landfill installation. Therefore, after applying the criteria, it was found that less than $50 \%$ of the entire region area is suitable for such an initiative leading to 31ranked sites with great aptitude to implementation of the landfill sanitary, according to multicriteria analysis by weighted overlay.
\end{abstract}

Key words: geoprocessing, urban planning, urban solid waste. 


\section{INTRODUÇÃO}

A principal consequência da organização do homem em sociedades urbanas foi o aumento substancial da geração de resíduos sólidos urbanos (RSU). Entretanto foi somente a partir da revolução industrial que os novos padrões de vida deram nova luz sobre a questão dos RSU, quando se criou o vínculo com a questão ambiental (KARAGIANNIDIS et al, 2005; SEARA et al, 2013).

Recentemente em consonância com a mobilização internacional iniciada pela ECO-92 é que o Brasil em 2010 com criou a Lei Federal n 12.305 que instituiu a Política Nacional dos Resíduos Sólidos (PNRS) com uma visão sistêmica da gestão dos resíduos sólidos, no que tange o desenvolvimento sustentável e a cooperação entre poder público e privado na responsabilidade compartilhada pelo ciclo de vida dos produtos e implantação da gestão integrada e gerenciamento ambientalmente adequado dos resíduos sólidos (BRASIL, 2010).

Assim, a disposição de resíduos sólidos resultantes de atividades de origem industrial, doméstica, hospitalar, comercial, agrícola, de serviços e de varrição e os lodos de sistemas de tratamento de água, bem como determinados líquidos cujas particularidades tornem inviável o seu lançamento na rede pública de esgotos ou corpos de água tem se tornado cada vez mais em riscos potenciais ao meio ambiente e à saúde pública (ABNT, 2004; MATEUS, 2012).

Para tanto, é o poder público municipal responsável pela gestão dos resíduos domiciliares, de limpeza pública e possui responsabilidade compartilhada com os geradores de pequenas quantidades de resíduos comerciais e entulhos, que variam de acordo com a legislação municipal. Enquanto que, a responsabilidade no gerenciamento dos resíduos de serviços de saúde, industriais, agrícolas, de portos, aeroportos, terminais rodoviários e ferroviários é dos geradores (IPT, 2001).

As etapas essenciais do planejamento da gestão integrada dos RSU são a coleta, tratamento e disposição final dos resíduos. Desta forma, depois de esgotadas todas as alternativas de tratamento, o rejeito resultante deve ser encaminhado à disposição final ambientalmente adequada, como os aterros sanitários. Segundo IPT (2001) aterro sanitário é um processo de disposição de resíduos sólidos no solo, fundamentado em critérios de engenharia e normas operacionais específicas, permitindo um confinamento seguro do ponto de vista ambiental e de saúde pública.

Não existe uma maneira única de implantação e operação de aterros, diversas técnicas são utilizadas, as quais umas são mais difundidas que outras, através de manuais, cartilhas, etc. Existe, contudo, normatização quanto aos itens mínimos de segurança e operação que este empreendimento deve possuir como previsto nas NBR 8.419 de 1992 e NBR 13.896 de 1997 (ABNT, 1992; ABNT, 1997).

Em média no Brasil são gastos anualmente $\mathrm{R} \$ 74,00 /$ hab com saneamento básico, ou seja, é estimado um gasto anual de $\mathrm{R} \$ 11,8$ bilhões, evidenciando a complexidade destas ações e a necessidade de planejamento (SNSA, 2009; SNIS, 2010).

Segundo Calvo et al. (2007), a seleção de áreas e as obras de aterro sanitário, devido aos seus impactos negativos, encontra uma série de entraves para sua implantação, desde de aspectos sociais, bem como de aspectos legais e ambientais, podendo ser inviabilizado ou eternamente postergado. Porém, a PNRS estabeleceu que até agosto de 2014 todos os lixões do país fossem substituídos por aterros sanitários controlados. Uma meta bastante ambiciosa, visto que mais de $30 \%$ dos municípios brasileiros com até 300 mil habitantes destinam seus resíduos em lixões (CNM, 2014). 
Entretanto um dos maiores entraves que os municípios encontram para se adequar a legislação no que diz respeito a construção e operação de aterros sanitários dentro das normas especificas da PNRS, diz respeito a não disponibilidade de área e recursos para o investimento em infraestrutura e logística. Uma possibilidade viável do ponto de vista econômico e ambiental aos municípios é sua organização na forma de consórcios, visando o uso conjunto de aterros sanitários, de maneira que todos os consorciados participem financeiramente com a implantação e manutenção, independente da área de implantação do aterro, definido a partir de critérios técnicos, ambientais e sociais.

Com relação ao processo técnico de pré-seleção de áreas para alocação de um aterro sanitário são considerados diversos fatores, normalmente separados em aspectos ambientais, restrições legais e critérios operacionais (CETESB, 1992; IPT, 2001; GOMES et al., 2003; CALVO et al., 2007; NI-BIN, 2008; MATEUS, 2012). Entretanto, o processo de seleção consiste na consideração não só de aspectos técnicos ambientais e operacionais ou de critérios restritivos, mas também devem ser observados aspectos socioeconômicos e pontuais que podem gerar entraves políticos, muitas vezes, definitivos na escolha do local (LINO, 2012).

O levantamento dessas informações geralmente é muito oneroso e de difícil integração e manipulação. Por outro lado, atualmente tem se empregado de forma sistemática novos procedimentos metodológicos que visam diminuir o custo financeiro e o emprego de recursos humanos nos estudos de seleção de áreas para a alocação de aterros sanitários. Desta forma, tem-se utilizado de um conjunto de tecnologias computacionais que permitem à coleta e tratamento de informações espaciais capaz de transformar e emitir informações de atributos do mundo real levando em conta suas características físicas, químicas e sociais, bem como sua distribuição espacial, com o objetivo de facilitar as interrelações com o espaço geográfico e providenciar estudos com finalidades especificas (CÂMARA; 2007; FONSECA e MOREIRA, 2011).

Segundo Batistella e Moran (2008), o uso e a difusão das geotecnologias vêm se tornando importante instrumento municipal de gestão pública, e a ampliação de bases cartográficas em toda a América Latina, têm permitido a ampliação de pesquisas direcionadas à gestão físico-territorial, cujas aplicações destacam-se em planejamento do uso da terra, análises de impactos ambientais, elaboração de zoneamentos, gestão de bacias hidrográficas, monitoramento de fontes poluidoras, etc.

Portanto, estudar áreas para disposição final de resíduos sólidos envolve a consideração de aspectos técnicos, ambientais e socioeconômicos, que possuem variabilidade e correlação espacial dentro da região de estudo. Desta maneira, o uso das diversas técnicas de geoprocessamento incorporado ao ambiente informatizado dos Sistemas de Informações Geográficas (SIG) apresenta um enorme potencial para este tipo de análise.

Assim, este trabalho apresenta um estudo voltado para a aplicação e seleção prévia de áreas hierarquizadas para alocação de um aterro sanitário, suportada dentro do ambiente SIG, na Região Metropolitana de Sorocaba. 


\section{METODOLOGIA}

\subsection{Caracterização da área de estudo}

A área de estudo é a Região Metropolitana de Sorocaba (RMS) que engloba 22 municípios paulistas (Figura 1), dos quais o município de Sorocaba é o de maior expressão econômica, administrativa e financeira com 610 mil habitantes (35,3\% da população da RMS) e esta localizada na região centro-oeste do estado, sendo a nona cidade mais populosa do estado e a quarta do interior paulista, concentrando $1,4 \%$ da população estadual. A região de estudo ocupa um território de aproximados $8.179,71 \mathrm{~km}^{2}$ e possui uma população estimada em 2012 de 1.726.409, o que a classifica como a 15ª maior Região Metropolitana do país, abrigando 3,9 \% da população do Estado (IBGE, 2013).

Figura 1 - Localização da Região Metropolitana de Sorocaba (RMS)

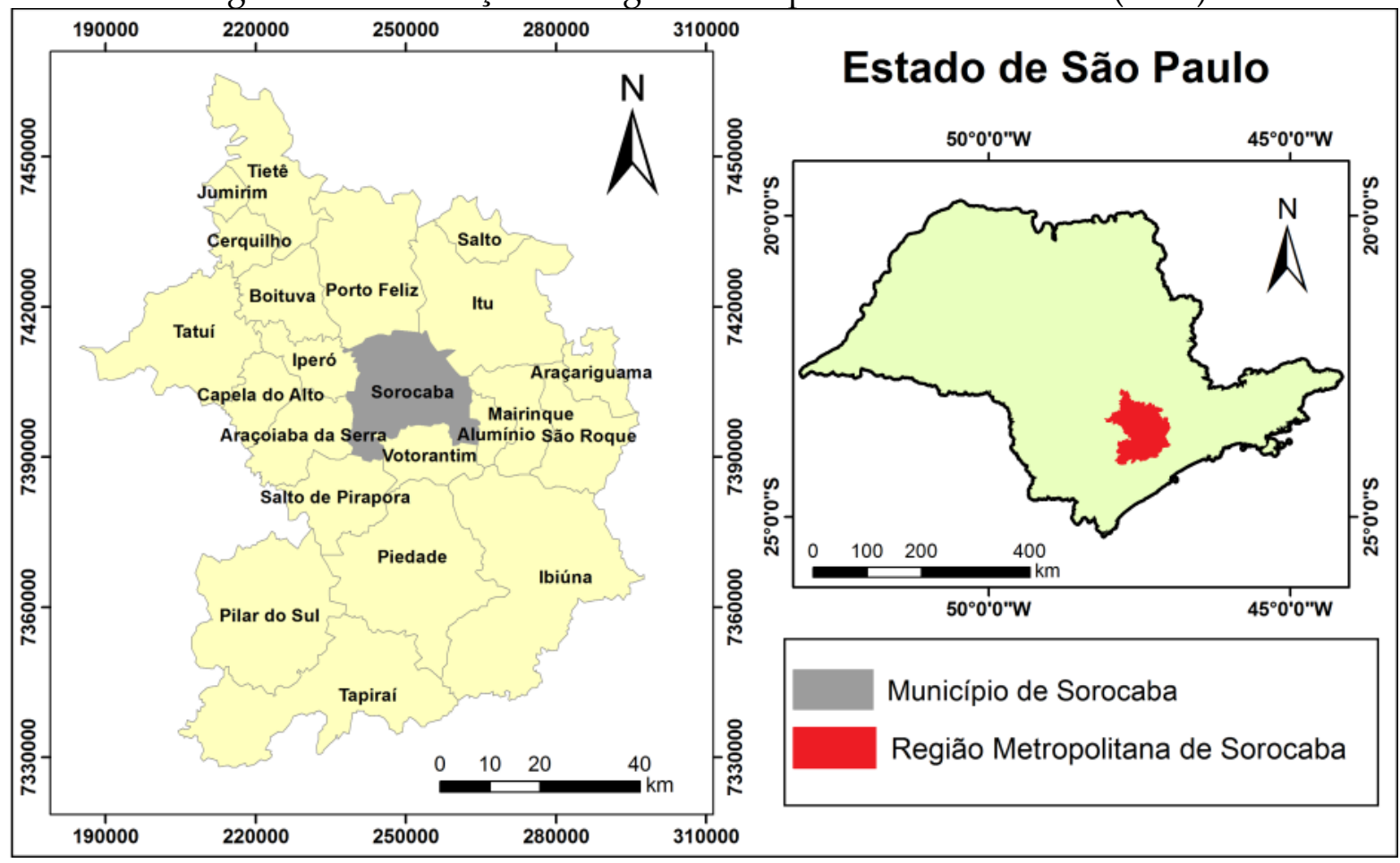

Fonte: Autor, 2014

A RMS apresenta diversas estruturas geológicas, com período de formação datando desde o Proterozóico Médio-Superior até o Quaternário. Na bacia destacam-se dois principais domínios litológicos metamórficos: o Domínio São Roque (metassedimentos e metabásicas) associados a diversos corpos graníticos, como é o caso dos granitos São Francisco e São Roque, pertencentes ao Domínio São Roque, e os granitos Ibiúna, Caucaia e Pilar do Sul, inseridos no Domínio Embu. Em relação à geomorfologia, as seguintes classes estão presentes na área de estudo: Mares de Morros, Morros com Serras Restritas, Morros Paralelos, Planícies Aluviais, Morros de Topos Achatados, Mesas Basálticas e Escarpas Festonadas. Quanto aos tipos de solos, existem três classes predominantes, o Argissolo, o Cambissolo e o Latossolo (IPT, 1981).

O principal curso d'água da região é o Rio Sorocaba, o mais importante afluente da margem esquerda do Rio Tietê, enquanto que, o reservatório de água subterrânea é o Aquífero Cristalino e o Tubarão, cuja produtividade pode ser classificada como de baixa a 
média (MCT, 2011). A vegetação da RMS é composta por floresta ombrófila densa, sendo caracterizada como uma área de tensão ecológica entre os domínios de Mata Atlântica e Cerrado (SALLES et al., 2008).

\subsection{Cálculo para estimativa de volume e áreas a destinação de RSU}

As áreas mínimas necessárias para alocação de um aterro sanitário foram calculadas levando-se em conta um tempo útil de 20 anos de operação. A estimativa de RSU ao longo dos anos em relação ao crescimento populacional de cada um dos municípios da RMS foi calculado a partir do levantamento dos censos do Instituto Brasileiro de Geografia e Estatística (IBGE) utilizando-se do modelo estatístico de regressão linear ajustado pelos mínimos quadrados. Para estimar a geração per capita anual de RSU (domiciliares, varrição e limpeza pública) encaminhados à disposição final, adotou-se o estudo de abrangência nacional realizado pelo Sistema Nacional de Informações sobre Saneamento ano base de 2012 (SNIS, 2014).

A massa bruta de Resíduos Sólidos Urbanos Destinados ao aterro sanitário (RSUD) gerada a cada ano, por município, foi obtida segundo a equação (1), apresentada a seguir:

$$
\operatorname{RSUD}_{\mathrm{i}}=\mathrm{P}_{\mathrm{i}} \times \mathrm{CGPC} \times 365 / 1000
$$

Onde:

RSUDi = massa de resíduo coletado no ano "i", em ton/ano;

$\mathrm{Pi}=$ População no ano "i";

CGPC = Coeficiente de Geração Per Capita de RSU, em kg/hab/ano.

$\mathrm{O}$ volume final do resíduo confinado foi obtido pelo fracionamento da massa de resíduo destinado (RSUD) e do peso específico do resíduo após compactação (DRS), somado ao volume de recobrimento da célula do aterro (VRC) com solo após o final de cada coleta, como mostrado na equação (2). O DRS utilizado foi calculado segundo Salamoni (2009), que analisou o peso específico dos resíduos sólidos confinados em diversas condições operacionais de aterros sanitários e chegou ao valor de $910 \mathrm{~kg} / \mathrm{m}^{3}$, em condições operacionais adequadas. Já o VRC considerado foi de 30\% a mais do volume do resíduo confinado (MELO, 2008).

$$
\mathrm{V}_{\mathrm{RSUD}}=\left(\frac{\mathrm{RSUD}}{\mathrm{DRS}}\right)+\mathrm{V}_{\mathrm{RC}}
$$

Onde:

VRSUD $=$ Volume do resíduo no aterro sanitário, $\mathrm{em}^{3}$;

DRS $=$ Peso específico do resíduo após compactação, em ton $/ \mathrm{m}^{3}$;

$\mathrm{VRC}=$ Volume do recobrimento da célula.

A área a ser ocupada pelo RSU enterrado foi calculada dividindo-se o volume do aterro pela altura de 30 metros para o condicionamento das células. Esta área representa somente o espaço do confinamento dos resíduos, sem considerar o espaço da infraestrutura do aterro. Segundo Ni-bin (2008), há a necessidade de um acréscimo de $50 \%$ da área de disposição para essas finalidades. A equação (3), mostra o cálculo da área necessária aos aterros sanitários. 
(3)

$$
A_{t}=\frac{V_{\text {RSUD }}}{h}+A_{I E}
$$

Onde:

At = Área total estimada do aterro sanitário;

$\mathrm{h}$ = Altura média de cada parcela do aterro;

$\mathrm{AIE}=$ Área de infraestrutura do aterro;

\subsection{Modelagem para seleção de áreas com base em critérios múltiplos e restritivos}

Foram considerados principalmente os critérios de ordem legal, como a legislação aplicada em âmbito nacional e estadual, e as municipais que fazem parte do consorcio, além das de ordem física e social, como aspectos do relevo, barreiras e distâncias entre a coleta e destinação.

As Áreas de Proteção Permanente (APP's) são consideradas áreas restritas à implantação do aterro sanitário e para defini-las foi utilizada a Lei Federal 12.651 de 2012 que define essas áreas, sendo consideradas as rampas do terreno com declividade maior que $45^{\circ}$ até uma distância mínima de $200 \mathrm{~m}$ devido a instabilidade e risco de erosão preconizada na NBR 13.896/97 e Portaria n¹24 de 1.980 do Ministério do Interior. Além disso, são restritivas todas as categorias de Unidades de Conservação (UC's) instituídas pela Lei Federal n. 9.985 de 2000.

Quanto as Áreas de Seguranças Aeroportuárias (ASA's), a resolução CONAMA 04/1995 é o marco regulatório que define os critérios de restrições de usos do solo ao redor de aeródromos e estabelece o raio mínimo de exclusão de $13 \mathrm{~km}$ de distância de quaisquer atividades que ofereçam riscos, entendidas como "foco de atração de pássaros". Entretanto, é aceito a flexibilização quanto ao raio de exclusão da ASA, sendo citada a distância de $8 \mathrm{~km}$ a partir do centro, a qual foi usada nesse estudo.

O entorno das rodovias que cortam o território da RMS representam um critério de ordem legal no que diz respeito à restrição de usos do solo no entorno das vias duplicadas. Segundo Gomes et al. (2003), as áreas situadas imediatamente no entorno dessas vias não devem receber um aterro sanitário devido aos perigos com relação à atração de pássaros e aos ruídos e gases emitidos. Para este estudo foi considerado como restritivo a distância mínima de $100 \mathrm{~m}$ das margens destas vias.

Com relação à análise da mancha urbana, foi levada em conta a rejeição da população a este tipo de empreendimento e a sua incompatibilidade, segundo o planejamento territorial municipal. Assim, nesse estudo foi considerada como área restrita a distância mínima de 500m de quaisquer agrupamentos urbanos, conforme definido pela NBR 13.896.

\subsection{Elaboração da base cartográfica de análise}

Foi obtido de cartas topográficas do IBGE na escala 1:50.000, com equidistância de $20 \mathrm{~m}$ informações referentes a hipsometria do relevo e da rede hidrográfica da área de estudo. Em seguida foi gerado um mapa de declividades expresso em porcentagem. De acordo com a NBR 13.896 são aptos a receber aterros sanitários os terrenos com até 30\% de declividade, podendo a critério do órgão ambiental local decidir pela aprovação de áreas com porcentagens superiores. Desta forma, este estudo considerou todas as áreas acima de $30 \%$ como áreas restritas. 
Os mapas de solos e litologia utilizados foram obtidos do banco de dados cartográficos do IBGE (2013) e estratificados em classes de aptidão à implantação do aterro sanitário com base nas características de cada conjunto de solos segundo a sua permeabilidade à infiltração, a disponibilidade local de material de empréstimo para o recobrimento das células, a capacidade de carga mecânica, a espessura do solo, a localização do aquífero e o grau de estruturação do material litológico de origem (CPRM, 2008).

O mapa de Uso do solo e cobertura vegetal foi gerado pelo processamento digital das imagens digitais do satélite Landsat 5 - TM, bandas 1, 2, 3, 4 e 5 adquiridas junto ao Instituto Nacional de Pesquisas Espaciais (INPE). O processamento de imagens iniciou-se pela realização da composição colorida R5G4B3, a qual foi escolhida para realizar a classificação das feições que cobrem a superfície terrestre. O processo de classificação utilizado foi o de máxima verossimilhança (MAXVER) supervisionado, assumindo quatro padrões visuais homogêneos: matas e reflorestamentos, agricultura, campos antrópicos e recursos hídricos. A categoria campos antrópicos englobou solos expostos, pastagens e afloramentos rochosos. As manchas urbanas foram extraídas manualmente em monitor sobre as imagens de satélite previamente tratadas considerando as características de rugosidade, contraste e heterogeneidade das manchas, procedimento com resultados superiores ao procedimento semiautomático, como as realizadas para categorias de cobertura com maiores homogeneidades.

\subsection{Avaliação multicritério para reclassificação e ponderação dos mapas base}

Em seguida os mapas foram reclassificados segundo um processo distinto de atribuição de notas para a realização da análise multicritérios. A nota atribuída variou de 0 a 10 (zero a dez), em que zero representa a menor aptidão e dez a melhor. As zonas desclassificadas à implantação do aterro por conta de alguma restrição foram excluídas da análise.

Os usos para rodovias, hidrografia, aeródromos e ASA's e manchas urbanas foram reclassificadas atribuindo-se notas de aptidão por importância segundo critérios de distância. As declividades, solos, litologia e demais usos do solo e cobertura vegetal foram reclassificados atribuindo-se notas de aptidão segundo critérios de importância ambiental, econômica e social no contexto urbano e rural.

A Tabela 1 mostra o resultado da classificação dos mapas e as notas segundo seus atributos, e a Tabela 2 os pesos atribuídos para os mapas que serão utilizados na análise multicritério que resultou no mapa de pontuação final das áreas aptas para implantação de aterro sanitário.

Tabela 1 - Classificação dos mapas segundo seus atributos

\begin{tabular}{c|c|c}
\hline Categoria & Proximidade/Critérios & Notas \\
\hline \multirow{4}{*}{$\begin{array}{c}\text { Corpos } \\
\text { Hídricos }\end{array}$} & $0-100 \mathrm{~m}$ & $\begin{array}{c}\text { restringid } \\
\text { o }\end{array}$ \\
\cline { 2 - 3 } & $100-200 \mathrm{~m}$ & 0 \\
\cline { 2 - 3 } & $200-300 \mathrm{~m}$ & 5 \\
\cline { 2 - 3 } & $200-400 \mathrm{~m}$ & 7 \\
\hline \multirow{2}{*}{$\begin{array}{c}\text { Mancha } \\
\text { Urbana }\end{array}$} & $>400 \mathrm{~m}$ & $\begin{array}{c}\text { restringid } \\
\text { ny }\end{array}$ \\
\cline { 2 - 3 } & $0-500 \mathrm{~m}$ & 5 \\
\hline
\end{tabular}




\begin{tabular}{|c|c|c|}
\hline & $1000-2000 m$ & 7 \\
\hline & $>2000 \mathrm{~m}$ & 10 \\
\hline \multirow{3}{*}{ ASA } & 0 a $8000 \mathrm{~m}$ & $\begin{array}{c}\text { restringid } \\
\mathrm{o}\end{array}$ \\
\hline & 8000 a $13000 \mathrm{~m}$ & 5 \\
\hline & $>13000 \mathrm{~m}$ & 10 \\
\hline \multirow{5}{*}{ Rodovias } & 0 a $100 \mathrm{~m}$ & $\begin{array}{c}\text { restringid } \\
\mathrm{o}\end{array}$ \\
\hline & 100 a $500 \mathrm{~m}$ & 2 \\
\hline & 500 a $1000 \mathrm{~m}$ & 7 \\
\hline & 1000 a $2000 \mathrm{~m}$ & 10 \\
\hline & $>2000 \mathrm{~m}$ & 5 \\
\hline \multirow{6}{*}{$\begin{array}{c}\text { Declividade } \\
(\%)\end{array}$} & $0-3$ & 10 \\
\hline & $3-5$ & 9 \\
\hline & $5-10$ & 8 \\
\hline & $10-20$ & 6 \\
\hline & $20-30$ & 3 \\
\hline & $>30$ & $\begin{array}{c}\text { restringid } \\
\mathrm{o}\end{array}$ \\
\hline \multirow{4}{*}{ Pedologia } & Argilossolo Vermelho-Amarelo & 10 \\
\hline & Cambissolo Háplico & 5 \\
\hline & Neossolo Litólico & 0 \\
\hline & Latossolo Vermelho & 10 \\
\hline \multirow{5}{*}{ Uso do solo } & Florestas/matas & 2 \\
\hline & Agricultura & 5 \\
\hline & Campos antrópicos & 8 \\
\hline & Água & $\begin{array}{c}\text { restringid } \\
\text { o }\end{array}$ \\
\hline & Mancha Urbana & $\begin{array}{c}\text { restringid } \\
\mathrm{o}\end{array}$ \\
\hline \multirow[b]{2}{*}{ Litologia } & $\begin{array}{c}\text { Formação Piranmóia (P3T1p), Grupo Itararé (C2P0i), NP3p_gamma_ } \\
\text { (Granitos foliados peraluminosos tipo S, Serra dos Lopes - 2Ssl, } \\
\text { Granitóides foliados indiferenciados quimicamente, Itapevi (0iv) e } \\
\text { Tapiraí (0tp), Granito peralcalino tipo A - 3Asf, Granitóides foliados e } \\
\text { ortognaisses, calcialcalinos, tipo I - Iib), Formação Pirapora do Bom Jesus, } \\
\text { Unidade carbonática (NP3srpc), Depósitos Aluvionares (Q2a), Formação } \\
\text { Piragibu (NP3srpi), Formação Boturuna (NP3srbt), Grupo Guatá (P0tt), } \\
\text { Grupo Votuverava, Unidade Xistos (Mp0vox), Super Grupo Açungui } \\
\text { (Mp2si) }\end{array}$ & 0 \\
\hline & $\begin{array}{l}\text { Grupo Votuverava, quartzito maciço e laminado (MP0voq), Complexo } \\
\text { plutônico alcalino Ipanema (K2_lambda_i), Formação Irati (P2i), } \\
\text { NP3p_gamma (Granitóides foliados peraluminosos, tipo S, Turvo - 0Stu, } \\
\text { Granitóides tectônica e quimicamente indiferenciados, Pica-pau - pp), } \\
\text { NP3e_gamma (Granitóides foliados peraluminosos, tipo S, Fumaça ou } \\
\text { Represa França - OSfu, Granitos foliados, quimicamente indiferenciados, } \\
\text { Caucaia - 2ca, Granitos foliados, quimicamente indiferenciados, } \\
\text { Laranjeiras - 2la, Granitóides foliados calcialcalinos - 0Isr, Granitóides } \\
\text { foliados peraluminosos, tipo S, Itatuba - 0Sib, Granitos foliados, } \\
\text { quimicamente indiferenciados, Rio das Pedras - rp), Grupo São Roque - }\end{array}$ & 5 \\
\hline
\end{tabular}


Formação estrado dos Romeiros (NP3srer), Magmatismo Relacionado ao Orógeno Socorro-Guaxupé (NP3s_gamma_2I), Complexo Varginha Guaxupé - Unidade paragnáissica migmatítica superior (NPvm), Complexo Embu (NPexm).

Complexo Varginha Guaxupé - Unidade ortognássica migmatítica intermediária (NPvog), NP3p_gamma_( Granitos foliados peraluminosos - 2Sps, Granitos foliados calcialcalinos, Tipo I, Piedade - 2Ipd, Granitóides tectônica e quimicamente indiferenciados, Pirapora - pr, Magmatismo relacionado ao orógeno paranapiacaba - Granito peralcalinos Tipo A, Serra da Batéia - 3Asb, Formação Iporanga - Granitóides foliados e ortognaisses, calcialcalinos tipo I, Agudos Grandes - OIag, Formação Iporanga - Granitóides tectônica e quimicamente indiferenciados, Tevere - te, 2Spd), NP3s_gamma_ (Granitos peralcalinos, tipo A, Itu - 3Ait, Granitos foliados, calcialcalinos, tipo I, Sorocaba - 2Iso), Formação Pirapora do Bom Jesus, Unidade vulcânica (NP3srpv), Formação Teresina (P3t), Formação Serra Alta (P23sa) , Bacia Serra Geral - Grupo São Bento (K0_delta_sg).

Os pesos atribuídos na sobreposição dos mapas foram ranqueados conforme sua importância para a implantação do aterro sanitário, onde o uso do solo obteve um peso muito alto e igual a $25 \%$ devido a presença de importantes classe restritivas quanto a implantação do aterro sanitário, como área urbanas e corpos hídricos, além disso, outros mapas foram gerados a partir do mapa do uso do solo.

Devido ao risco de contaminação da água e proliferação de doenças causadas por animais e insetos foi atribuído um peso alto igual a $15 \%$ aos mapas de proximidade à hidrografia e manchas urbanas. Em relação ao mapa de declividade também foi atribuído um peso alto igual a 15\%, uma vez que, a inclinação do terreno está diretamente associada ao seu grau de estabilidade contra erosão e deslizamentos e, portanto, é um fator importante na escolha de áreas para aterro sanitário.

Quanto a proximidade à vias foi atribuído um peso médio igual a 10\% devido a presença constante de transportes transportando resíduos aumentar o riscos de acidentes bem como o aumento da presença de animais nas vias que também aumentam a incidência de acidentes, além do incômodo com relação ao cheiro provenientes destes resíduos. Ao mapa de litologia também foi um peso médio igual a 10\% devido as características físicas do solo, como impermeabilidade, estarem associadas à rocha formadora deste solo.

Os mapas de proximidade à ASA e pedologia receberam um peso baixo igual a $5 \%$, pois o mapa de proximidade à ASA não traz tantos riscos quanto os outros tema estudados e o mapa pedológico apresenta características do solo que são influenciadas pela rocha formadora e pelo intemperismo pelo qual foi exposto e como o litológico traz informações da rocha formadora, o peso atribuído ao mapa pedológico foi baixo, uma vez que, fora atribuído peso ao mapa litológico. 
Tabela 2 - Pesos atribuídos aos mapas na sobreposição ponderada

\begin{tabular}{c|c}
\hline Mapas & PESOS (\%) \\
\hline Proximidade à vias & 10 \\
\hline Proximidade à ASA & 5 \\
\hline Declividade & 15 \\
\hline Proximidade à hidrografia & 15 \\
\hline Proximidade às manchas urbanas & 15 \\
\hline Usos e ocupação do solo & 25 \\
\hline Pedologia & 5 \\
\hline Litologia & 10 \\
\hline Total (\%) & $\mathbf{1 0 0}$ \\
\hline
\end{tabular}

Em seguida foram selecionadas as áreas com as dimensões aproximadas da demanda estimada e requerida para a destinação dos resíduos sólidos gerados pelos municípios da RMS. O ranqueamento e a escolha das áreas basearam-se na pontuação final de cada área selecionada. As áreas melhores qualificadas foram relacionadas com o quadro da disposição atual dos resíduos sólidos urbanos dentro dos municípios para destacar as zonas dentro do território com potencial para implantação imediata de um aterro sanitário com solução consorciada através da análise aprofundada das áreas hierarquizadas.

\section{RESULTADOS E DISCUÇÕES}

\subsection{Análise dos RSU gerados na RMS}

A disposição final dos resíduos sólidos urbanos gerados pelos habitantes RMS apresenta um quadro bom com relação ao envio ambientalmente adequado, 19 municípios dispõem seus resíduos em aterro sanitário com condições adequadas de operação, segundo o Índice de Qualidade de Resíduos (IQR) ano base 2012 da CETESB (2013), o que representa 97,2\% do total em massa gerado, sendo que somente os municípios de Araçoiaba da Serra, Capela do Alto e Piedade apresentam enquadramento em condições inadequadas de operação $(\mathrm{IQR}<7,0)$.

Importante ressaltar o fato de nove municípios gerarem menos de 10t/dia de RSU Alumínio, Capela do Alto, Araçoiaba da Serra, Araçariguama, Iperó, Jumirim, Piedade, Pilar do Sul, Tapiraí -, o que os enquadra na categoria de pequenos geradores, para os quais a CETESB permitem assumir um procedimento simplificado de licenciamento ambiental e operação da disposição final de seus resíduos, os chamados aterros em valas, ou aterros de pequeno porte (CETESB, 2010).

A alternativa por relegar a destinação final a um aterro sanitário particular é adotada por 9 municípios da RMS, porém, apesar de desonerar o município do seu gerenciamento, representa um custo elevadíssimo para a municipalidade. Por exemplo, Sorocaba, dispõe seus resíduos em aterro particular em Iperó e paga 68,00 R \$/tonelada (PMS, 2014) somente para a sua disposição final, o que representa um gasto anual estimado de aproximadamente 8,86milhões de reais, além dos gastos com transporte.

A Tabela 3 apresenta a estimativa da geração per capita diária de resíduos sólidos dentro da RMS. 
Tabela 3 - Estimativa da geração per capita diária de RSU

\begin{tabular}{c|c|c|c|c|c}
\hline Município & $\begin{array}{c}\text { População } \\
\text { total } \\
\mathbf{( 2 0 1 1 )}\end{array}$ & $\begin{array}{c}\text { Índice } \\
\mathbf{( k g / h a b / d i a )}\end{array}$ & Município & $\begin{array}{c}\text { População } \\
\text { total } \\
\mathbf{( 2 0 1 1 )}\end{array}$ & $\begin{array}{c}\text { Índice } \\
\mathbf{( k g / h a b / d i a )}\end{array}$ \\
\hline Sorocaba & 593.776 & 0,888 & Mairinque & 43.473 & 0,681 \\
\hline Alumínio & 16.961 & 1,154 & Piedade & 52.298 & 0,766 \\
\hline Araçariguama & 17.506 & 0,748 & Pilar do Sul & 27.206 & 0,669 \\
\hline $\begin{array}{c}\text { Araçoiaba da } \\
\text { Serra }\end{array}$ & 28.007 & 0,669 & Porto Feliz & 49.153 & 0,698 \\
\hline Boituva & 49.385 & 1,027 & Salto & 106.465 & 0,613 \\
\hline Capela do Alto & 17.785 & 0,308 & $\begin{array}{c}\text { Salto de } \\
\text { Pirapora }\end{array}$ & 40.521 & 0,430 \\
\hline Cerquilho & 40.393 & 0,513 & São Roque & 79.757 & 0,684 \\
\hline Ibiúna & 71.742 & 0,606 & Tapiraí & 7.970 & 0,440 \\
\hline Iperó & 29.062 & 0,566 & Tatuí & 108.393 & 0,669 \\
\hline Itu & 155.589 & 0,924 & Tietê & 37.447 & 0,669 \\
\hline Jumirim & 2.845 & 1,090 & Votorantim & 109.798 & 0,724 \\
\hline
\end{tabular}

A estimativa de crescimento populacional dos municípios da RMS utilizando o ajuste linear permitiu avaliar um indicativo do potencial de geração RSU. A Tabela 4 apresenta os valores acumulados da estimativa populacional e de geração diária de resíduos sólidos urbanos destinados a aterros, contidos na Tabela 3 calculados para os próximos 20 anos considerados a partir do ano base 2014 .

Tabela 4 - Estimativa da população e da geração RSU para 20 anos

\begin{tabular}{|c|c|c|c|c|c|}
\hline \multirow[b]{2}{*}{ Município } & \multicolumn{2}{|c|}{ Projeções para 2034} & \multirow[b]{2}{*}{ Município } & \multicolumn{2}{|c|}{ Projeções para 2034} \\
\hline & População & $\begin{array}{l}\text { Índice } \\
(t / \text { dia) }\end{array}$ & & População & $\begin{array}{l}\text { Índice } \\
\text { (t/dia) }\end{array}$ \\
\hline Sorocaba & 863.080 & 766,84 & Mairinque & 59.609 & 40,57 \\
\hline Alumínio & 22.518 & 25,98 & Piedade & 68.529 & 52,48 \\
\hline Araçariguama & 30.327 & 22,68 & Pilar do Sul & 34.106 & 22,8 \\
\hline Araçoiaba da Serra & 45.303 & 30,29 & Porto Feliz & 59.974 & 41,89 \\
\hline Boituva & 82.168 & 84,39 & Salto & 142.036 & 87 \\
\hline Capela do Alto & 26.125 & 8,05 & $\begin{array}{l}\text { Salto de } \\
\text { Pirapora }\end{array}$ & 57.541 & 24,74 \\
\hline Cerquilho & 64.777 & 33,22 & São Roque & 112.417 & 76,93 \\
\hline Ibiúna & 94.916 & 57,5 & Tapiraí & 9.847 & 4,33 \\
\hline Iperó & 52.474 & 29,68 & Tatuí & 146.206 & 97,84 \\
\hline Itu & 212.505 & 196,45 & Tietê & 50.066 & 33,47 \\
\hline Jumirim & 4.704 & 5,13 & Votorantim & 145.840 & 105,65 \\
\hline
\end{tabular}

O crescimento populacional projetado para a RMS de 2013 até o ano de 2034 foi estimado em $37,4 \%$. Apesar de a geração diária total de resíduos chegar a 1.848 t/dia em 2034, a expectativa é de que três municípios ainda permaneçam abaixo da produção de 10 t/dia, como Capela do Alto, Jumirim e Tapiraí. 


\subsection{Dimensionamento da área do aterro sanitário}

Com base nas projeções populacionais e de geração de RSU foi estimada o tamanho de área necessária para alocação de aterro sanitário na RMS (Tabela 5).

Tabela 5 - Estimativa do total de resíduos sólidos urbanos coletados e das áreas necessárias para o aterro sanitário, segundo o horizonte de 20 anos

\begin{tabular}{|c|c|c|c|c|c|}
\hline \multirow[b]{2}{*}{ Município } & \multicolumn{2}{|c|}{ Projeções para 2034} & \multirow[b]{2}{*}{ Município } & \multicolumn{2}{|c|}{ Projeções para 2034} \\
\hline & $\begin{array}{c}\text { RSU } \\
\text { acumulado (t) }\end{array}$ & Área (ha) & & $\begin{array}{c}\text { RSU } \\
\text { acumulado (t) }\end{array}$ & $\begin{array}{c}\text { Área } \\
\text { (ha) }\end{array}$ \\
\hline Sorocaba & 5.467 .644 & 38,01 & Mairinque & 298.793 & 2,08 \\
\hline Alumínio & 187.957 & 1,31 & Piedade & 395.138 & 2,75 \\
\hline Araçariguama & 149.766 & 1,04 & Pilar do Sul & 172.933 & 1,2 \\
\hline $\begin{array}{c}\text { Araçoiaba da } \\
\text { Serra }\end{array}$ & 207.999 & 1,45 & Porto Feliz & 322.498 & 2,24 \\
\hline Boituva & 573.412 & 3,99 & Salto & 647.503 & 4,5 \\
\hline Capela do Alto & 57.448 & 0,4 & Salto de Pirapora & 179.260 & 1,25 \\
\hline Cerquilho & 229.141 & 1,59 & São Roque & 563.493 & 3,92 \\
\hline Ibiúna & 427.332 & 2,97 & Tapiraí & 33.489 & 0,23 \\
\hline Iperó & 196.520 & 1,37 & Tatuí & 724.023 & 5,03 \\
\hline Itu & 1.447 .118 & 10,06 & Tietê & 247.335 & 1,72 \\
\hline Jumirim & 35.354 & 0,25 & Votorantim & 784.263 & 5,45 \\
\hline
\end{tabular}

É importante ressaltar, que o dimensionamento realizado não foi feito com o objetivo de se obter somente a área necessária para a instalação de um único aterro sanitário para toda a região, mas também de analisar as demandas por áreas presente em cada município para que se pudessem evidenciar os potenciais de agrupamento destes segundo a geração de RSU dentro do horizonte de estudo.

\subsection{Geração do mapa de áreas potenciais}

As áreas excluídas por critérios legais ocuparam uma superfície de 464.759 ha, ou seja, aproximadamente $56,5 \%$ da região. Apesar de mais da metade das áreas da região de estudo terem sido previamente excluídas já no processo de classificação, este resultado era esperado devido ao grande número de restrições impostas à alocação deste tipo de empreendimento.

Visto a quantidade de RSU gerados e o número de municípios da RMS, a seleção de uma área para atender a demanda do ponto de vista técnico e econômico é limitada, tal que o município de Sorocaba é o que necessita de uma maior área para deposição dos RSU, entretanto, é também o que apresenta o menor número de áreas aptas.

O mapa das pontuações finais (Figura 2) apresenta as seguintes categorias de áreas: Áreas não recomendadas, Áreas recomendadas com restrição e as Áreas recomendadas. Esta divisão foi realizada com o objetivo de orientar a busca por áreas melhores ranqueadas, já que não há homogeneidade entre as zonas de mesma pontuação, isto é, foram observadas regiões vizinhas com mais de 4 pontos de diferença entre si. 
Esta foi uma característica observada na área de estudo, o que dificulta a possibilidade de encontrar somente uma zona com pontuação alta, e sim, diversas áreas que após a ponderação dos critérios envolvidos apresentem propriedades favoráveis que contrabalanceiem as negativas.

Figura 2 - Pontuação final das áreas compatíveis à instalação do aterro sanitário

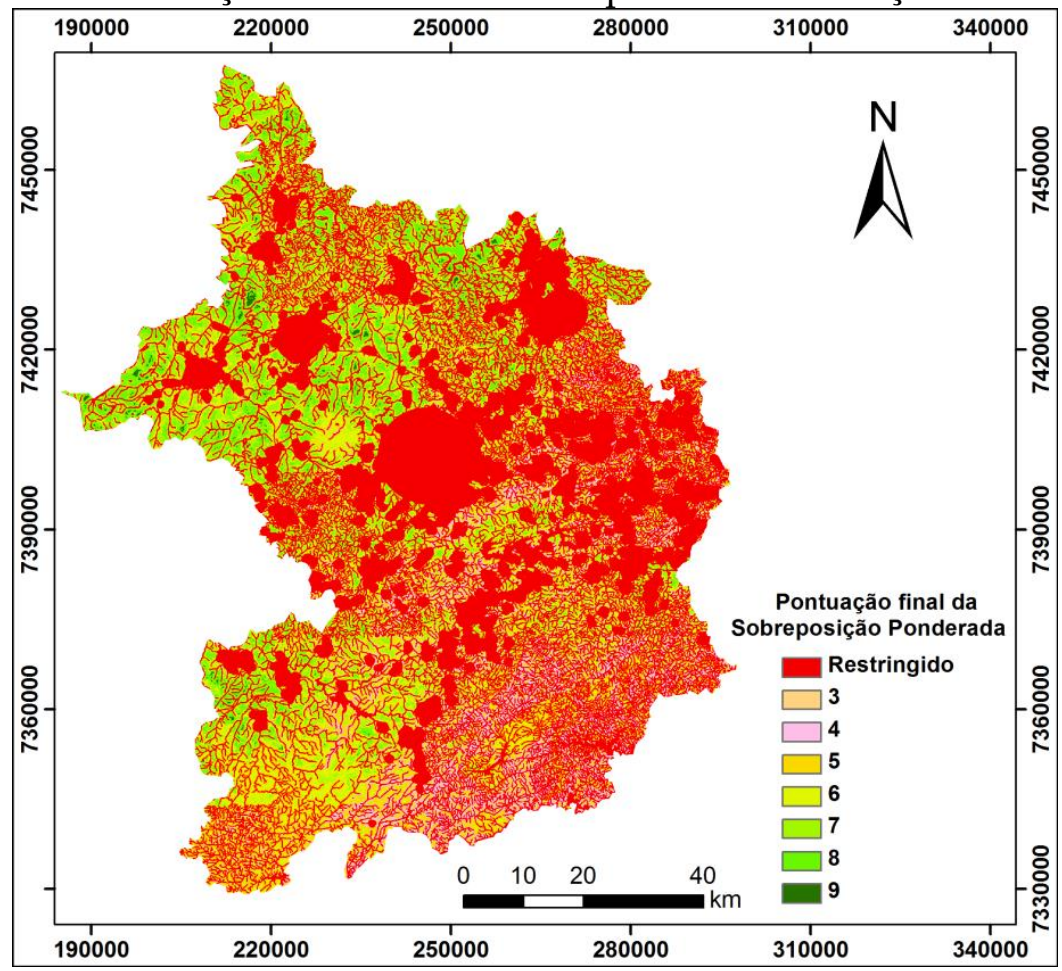

Pela divisão definida para as áreas segundo a sua pontuação, obtiveram-se o total de áreas classificadas, em hectares:

- Áreas não recomendadas (notas de 1 a 4): 43.438 ha;

- Áreas recomendadas com restrições (notas de 5 a 7): 27.3278 ha;

- Áreas recomendadas (notas acima de 8): 39.201 ha.

Ainda que mais do que suficientes áreas tenham sido classificadas como recomendadas, muitas dessas podem encontrar-se fragmentadas ou com alguma restrição pontual que a desclassificaria para tal finalidade, como descrito anteriormente. Portanto, para o processo de pré-seleção, ainda foi realizada um refinamento "zona a zona" pelas áreas classificadas a fim de elencar áreas com maior potencial segundo outros critérios, como por exemplo, locacionais e de distância dos centros geradores de RSU.

\subsection{Hierarquização de áreas pré-selecionadas}

Segundo estimado, seriam necessários 92,80ha para abrigar vários aterros sanitários capazes de confinar todos os resíduos gerados na área de estudo até o ano de 2034.

Dessa forma, foi produzida uma lista final hierarquizada de várias áreas compatíveis destacadas na Figura 3, além de uma zona com municípios destacados, na qual foi realizada uma seleção de área para alocação de um aterro sanitário com solução consorciada. 
Figura 3 - Mapa das áreas selecionadas para hierarquização e a zona destacada para estudo de seleção de aterro consorciado

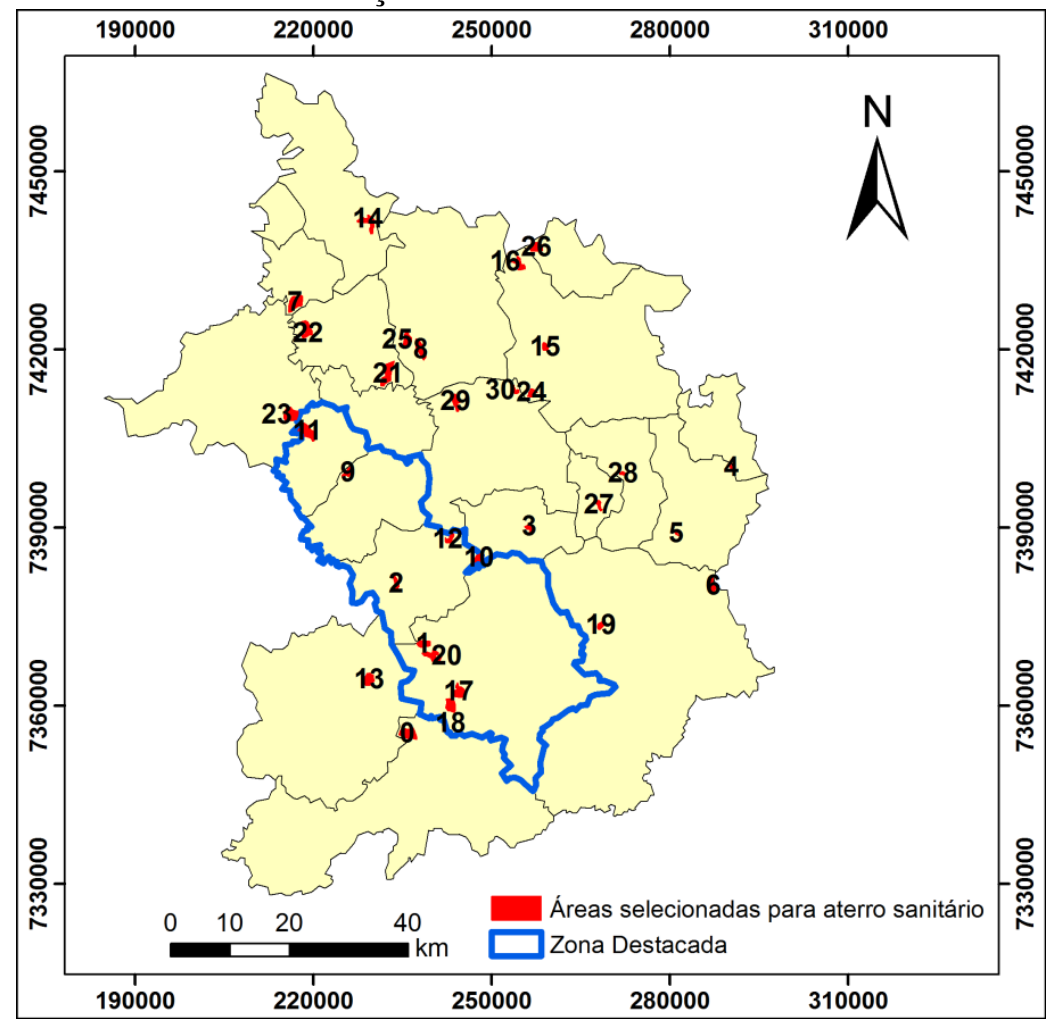

Nos municípios de Jumirim e Iperó respectivamente, não foram selecionadas áreas para hierarquização, o primeiro por estar localizado na APA Tietê e possuir poucas vias de acesso com baixa produção de resíduos, e o segundo por ter um aterro particular recéminaugurado, em 2010, e por estar inserido na Floresta Nacional de Ipanema.

A Tabela 5 mostra o ranqueamento das áreas selecionadas conforme pontuação final.

Conforme os critérios adotados, a área melhor pontuada é a de número 7, com nota final 8,3 e área de 444,8 hectares, localizada a noroeste da Figura 3, no município de Cerquilho. Contudo, tomando por base o critério posicionamento das áreas dentro da região de estudo, as quatro primeiras colocadas no ranqueamento encontram-se distantes dos grandes polos geradores de resíduos. Em contrapartida, as áreas 25, 23 e 2 (quinta, sexta, e sétima colocadas), localizadas respectivamente na região norte, noroeste e oeste da Figura 3, encontram-se melhor localizadas em relação aos municípios que geram um maior volume de RSU.

Com relação à área destacada em azul na Figura 3, ela foi escolhida para ter sido realizado um estudo de alternativa de alocação de aterro sanitário com solução consorciada devido ao enquadramento negativo do IQR (CETESB, 2012) em que três dos quatro municípios incluídos, sendo estes, Araçoiaba da Serra (9), Capela do Alto (11) e Piedade (1, 17, 18 e 20). A dificuldade que os municípios têm experimentado na destinação final de seus resíduos pode representar uma oportunidade de, em conjunto, contornarem esta situação e se adequarem. 
Tabela 5 - Ranking das áreas selecionadas conforme pontuação final

\begin{tabular}{c|c|c|c|c|c|c|c}
\hline Ranking & $\begin{array}{c}\text { Área } \\
\text { Selecionada }\end{array}$ & $\begin{array}{c}\text { Pontuação } \\
\text { final }\end{array}$ & $\begin{array}{c}\text { Área } \\
\text { (ha) }\end{array}$ & Ranking & $\begin{array}{c}\text { Área } \\
\text { Selecionada }\end{array}$ & $\begin{array}{c}\text { Pontuação } \\
\text { final }\end{array}$ & $\begin{array}{c}\text { Área } \\
\text { (ha) }\end{array}$ \\
\hline $1^{\circ}$ & 7 & 8,3 & 444,8 & $17^{\circ}$ & 10 & 7,3 & 152 \\
\hline $2^{\circ}$ & 16 & 8,1 & 226,7 & $18^{\circ}$ & 30 & 7,29 & 88,2 \\
\hline $3^{\circ}$ & 26 & 8 & 241,2 & $19^{\circ}$ & 29 & 7,26 & 230,2 \\
\hline $4^{\circ}$ & 14 & 7,9 & 333,3 & $20^{\circ}$ & 3 & 7,1 & 121,4 \\
\hline $5^{\circ}$ & 25 & 7,9 & 256,7 & $21^{\circ}$ & 1 & 6,5 & 202 \\
\hline $6^{\circ}$ & 23 & 7,7 & 431,7 & $22^{\circ}$ & 13 & 6,5 & 286,8 \\
\hline $10^{\circ}$ & 24 & 7,6 & 116,8 & $23^{\circ}$ & 17 & 6,5 & 328,8 \\
\hline $7^{\circ}$ & 2 & 7,6 & 117,2 & $24^{\circ}$ & 12 & 6,4 & 137,1 \\
\hline $8^{\circ}$ & 8 & 7,6 & 342,5 & $25^{\circ}$ & 18 & 6,4 & 310 \\
\hline $9^{\circ}$ & 9 & 7,6 & 138,3 & $26^{\circ}$ & 19 & 6,4 & 119,6 \\
\hline $11^{\circ}$ & 15 & 7,5 & 104,7 & $27^{\circ}$ & 28 & 6,4 & 142,7 \\
\hline $12^{\circ}$ & 0 & 7,4 & 404,5 & $28^{\circ}$ & 20 & 6,3 & 299,2 \\
\hline $13^{\circ}$ & 6 & 7,4 & 159 & $29^{\circ}$ & 4 & 6,2 & 36,7 \\
\hline $14^{\circ}$ & 11 & 7,4 & 440,7 & $30^{\circ}$ & 27 & 5,9 & 142,8 \\
\hline $15^{\circ}$ & 21 & 7,4 & 427,5 & $31^{\circ}$ & 5 & 5,8 & 33 \\
\hline $16^{\circ}$ & 22 & 7,4 & 325,1 & & Área Total & & 7141,2 \\
\hline
\end{tabular}

Ressalta-se que pela proximidade da zona destacada a dois dos principais polos geradores de resíduos da região de estudo, (Sorocaba e Votorantim), a instalação de um aterro sanitário nesta região possui um grande potencial para abrigar uma solução consorciada de disposição de resíduos que atenda a demanda destes dois importantes polos.

Ao todo, nove áreas foram localizadas dentro da zona destacada $(1,2,9,10,11,12$, 17,18 e 20). Na Tabela 6 são mostrados os resultados da análise aprofundada das áreas selecionadas. Apesar das áreas 11 (região noroeste) e 17 (região sul), apresentarem boa pontuação pela análise multicritério e serem grandes o suficiente para alocar um aterro sanitário, encontram restrições devido à presença de grande quantidade de matas, o que aumenta o impacto da instalação e as tornam desfavoráveis. Enquanto isso, as áreas 1 (região sudoeste) e 18 (região sul) possuem terreno com alta declividade e presença de matas, fatores que dificultam a instalação deste tipo de empreendimento.

As áreas de número 02, 10 e 12, todas localizadas na região oeste e inseridas no município de Salto de Pirapora, junto da área de número 09, localizada na região noroeste, no município de Araçoiaba da Serra são as que se encontram mais próximos dos maiores polos geradores de RSU.

As áreas 09 e 12 apesar da proximidade com os polos geradores foram descartadas após uma análise mais detalhada em campo, visto que estão fragmentadas por construções e demarcações de propriedades rurais imperceptíveis nas imagens utilizadas neste estudo devido a baixa resolução. 
Tabela 6 - Análise da zona destacada para seleção de áreas de aterro sanitário com solução consorciada

\begin{tabular}{c|c|c|c|c|c|c}
\hline $\begin{array}{c}\text { Área } \\
\text { Selecionada }\end{array}$ & $\begin{array}{c}\text { Nota pela } \\
\text { análise } \\
\text { multicritério }\end{array}$ & $\begin{array}{c}\text { Área } \\
\text { (ha) }\end{array}$ & $\begin{array}{c}\text { Distância } \\
\text { aproximada } \\
\text { às vias (m) }\end{array}$ & $\begin{array}{c}\text { Declividade } \\
\text { média (\%) }\end{array}$ & $\begin{array}{c}\text { Uso do solo } \\
\text { predominante }\end{array}$ & $\begin{array}{c}\text { Presença } \\
\text { de matas }\end{array}$ \\
\hline 1 & 6,5 & 202,0 & $0^{*}$ & 22 & $\begin{array}{c}\text { Campo } \\
\text { antrópico }\end{array}$ & media \\
\hline 2 & 7,6 & 117,2 & 200 & 4 & $\begin{array}{c}\text { Campo } \\
\text { antrópico }\end{array}$ & baixa \\
\hline 9 & 7,6 & 138,3 & 400 & 10 & $\begin{array}{c}\text { Campo } \\
\text { antrópico }\end{array}$ & baixa \\
\hline 10 & 7,3 & 152,0 & $<100$ & 12 & $\begin{array}{c}\text { Campo } \\
\text { antrópico }\end{array}$ & baixa \\
\hline 11 & 7,4 & 440,7 & $<100$ & 5 & Florestas & alta \\
\hline 12 & 6,4 & 137,1 & $0^{*}$ & 3 & $\begin{array}{c}\text { Campo } \\
\text { antrópico }\end{array}$ & nenhuma \\
\hline 17 & 6,5 & 328,8 & $0^{*}$ & 22 & Florestas & alta \\
\hline 18 & 6,4 & 310,0 & 200 & 38 & $\begin{array}{c}\text { Campo } \\
\text { antrópico }\end{array}$ & alta \\
\hline 20 & 6,3 & 299,2 & $0^{*}$ & 16 & $\begin{array}{c}\text { Campo } \\
\text { antrópico }\end{array}$ & media \\
\hline
\end{tabular}

*Obs: áreas que são cortadas por estradas

A área 10 mostrou-se a mais adequada, pois está às margens de uma rodovia importante e sem fragmentação aparente do território. A área está ocupada em sua maior parte por uma vegetação secundária rasteira degradada e uma parcela por floresta de Eucaliptos. Esta área, pelos critérios utilizados nesta metodologia, foi a melhor classificada para a implantação de um aterro sanitário com solução consorciada para a zona destacada que atenderia aos principais polos geradores de RSU.

\section{CONCLUSÃO}

Com respeito ao ranqueamento final das áreas pré-selecionadas para implantação de aterros sanitários os resultados foram satisfatórios, considerando a base de dados disponível. É importante ressaltar que nenhuma das áreas foi classificada como recomendada sem restrições (nota maior ou igual a 8), o que mostra a dificuldade de encontrar áreas que não possuam nenhuma restrição para a implantação de um empreendimento deste tipo, pois os impactos negativos são muitos e dificilmente podem ser totalmente contornados. Foi possível extrair 31 áreas compatíveis em toda a extensão do território, sendo que a lista ranqueada representa o produto final da pré-seleção das áreas, onde devem ser realizadas amostras de campo e consideradas as questões políticas para analisar a viabilidade da efetiva implantação de um aterro sanitário no local.

A partir dos resultados deste estudo foi possível identificar os municípios com demanda potencial para implantação de um aterro sanitário com solução consorciada na RMS. O aprofundamento do estudo nas áreas selecionadas inseridas na zona destacada 
permitiu a escolha de quatro com grande potencial de implantação de um aterro sanitário que supririam a demanda existente.

A seleção de áreas para a implantação de aterros sanitários envolve a consideração de muitos aspectos de ordem técnica, ambiental e legal, o que exige a manipulação de uma grande quantidade de dados e torna o processo bastante complexo e de difícil replicação em algumas regiões devido à falta de dados. Desta forma, a metodologia empregada na construção de um banco de dados pode ser constantemente atualizado e é fundamental para o aprofundamento de estudos multitemáticos capazes de fortalecer a integração entre municípios em prol do desenvolvimento sustentável da região e servir como base na elaboração de estudos com suporte na tomada de decisão pelos gestores públicos.

\section{REFERÊNCIAS BIBLIOGRÁFICAS}

ABNT, ASSOCIAÇÃO BRASILEIRA DE NORMAS TÉCNICAS. NBR 10004: Resíduos sólidos - Classificação. Segunda edição. Rio de Janeiro, RJ, 2004. 71 p.

ABNT, ASSOCIAÇÃO BRASILEIRA DE NORMAS TÉCNICAS. NBR 13896/1997: Aterros de resíduos não perigosos - Critérios para projeto, implantação e operação. Rio de Janeiro, RJ, 1997.

ABNT, ASSOCIAÇÃO BRASILEIRA DE NORMAS TÉCNICAS. NBR 8.419: Apresentação de projetos de aterros sanitários de resíduos sólidos urbanos. São Paulo, 1992.

BATISTELLA, M.; MORAN, E, F. Geoinformação e monitoramento ambiental na América Latina. São Paulo: SENAC São Paulo. 2008.

BRASIL. Decreto ${ }^{\circ} 7404$ de 23 de dezembro de 2010. Regulamenta a lei $n^{\circ} 12651$ de 2010 e dá outras previdências. Diário Oficial [da] República Federativa do Brasil, Poder Executivo, Brasília - DF, 2010.

CÂMARA, G.; FONSECA, F. Information policies and open source software in developing countries. J. Am. Soc. Inf. Sci., 58: p.121-132, 2007. doi: 10.1002/asi.20444

CALVO, F. et al. Implementation of a new environmental impact assessment for municipal waste landfills as tool for planning and decision-making process. Renewable And Sustainable Energy Reviews, Granada, Spain, v. 11, n. 1, p.98-115, jan. 2007. doi: 10.1016/j.rser.2004.12.003

CETESB, Companhia Ambiental do Estado de São Paulo. Inventário Estadual de Resíduos Sólidos Urbanos de 2012. São Paulo : CETESB, 2013.

CETESB, Companhia Ambiental do Estado de São Paulo. Manual de operação de aterro sanitário em valas. São Paulo : CETESB, 2010.

CETESB, Companhia Ambiental do Estado de São Paulo. Norma 94.241. Critérios para submissão de projetos de aterros sanitários para licenciamento ambiental. São Paulo - SP. 1992. 
CNM, CONFEDERAÇÃO NACIONAL DOS MUNICÍPIOS. (Org.). Coletiva de Imprensa sobre Resíduos Sólidos e o prazo da Lei 12.305/2010. Brasília, 2014. 62p. Disponível em: <http://www.cnm.org.br/portal/images/stories/Links/28072014_Coletiva__Resduos.pdf>. Acesso em: 04 ago. 2014.

CPRM, Companhia de Pesquisa de Recursos Minerais. Geodiversidade do Brasil: conhecer o passado, para entender o presente e prever o futuro. Rio de Janeiro: CPRM, 2008. 264 p.

GOMES, L. P.; MARTINS, F. B. Projeto, Implantação e Operação de Aterros Sustentáveis de Resíduos Sólidos Urbanos para Municípios de Pequeno Porte. Rio de Janeiro: ABES, RiMa, 2003.

IBGE, Instituto Brasileiro de Geografia e Estatística. Pesquisa Populacional por municípios: censos anteriores, censo 2010 e projeções futuras. IBGE, 2013.

IPT, Instituto de Pesquisas Tecnológicas do Estado de São Paulo. Mapa Geológico do Estado de São Paulo. Nota Explicativa. São Paulo. IPT Monografias, no 6, v. 1, 126 p. 1981.

IPT, Instituto de Pesquisas Tecnológicas do Estado de São Paulo. Disposição Final do Lixo. In: Lixo Municipal: Manual de Gerenciamento Integrado. 2a Ed. São Paulo: IPT/CEMPRE, 2001. p. 251-290.

KARAGIANNIDIS A.; PERKOULIDIS G.; PAPADOPOULOS A.M.; MOUSSIOPOULOS N. AND TSATSARELIS TH. Characteristics of wastes from electric and electronic equipment in Greece: results of a field survey. Waste Management \& Research: 23, p. 381-388, 2005.

LINO, A. M, ISMAIL, K. A. R. Analysis of the potential of municipal solid waste in Brazil. Environmental Development, Campinas, v. 4, n. 1, p.105-113, set. 2012.

MATEUS, M. S. C. ; MACHADO, S. L.; BARBOSA, M. C. An attempt to perform water balance in a Brazilian municipal solid waste landfill. Waste Management, Brazil, v. 32, n. 3, p.471-481, Dec. 2012.

MCT, Ministério da Ciência e Tecnologia. Atlas dos Remanescentes Florestais da Mata Atlântica: Período de 2008-2010. FUNDAÇÃO SOS MATA ATLÂNTICA E INSTITUTO NACIONAL DE PESQUISAS ESPACIAIS. São Paulo, p. 122. 2011.

MOREIRA, M. A. Fundamentos do Sensoriamento Remoto e Metodologias de Aplicação. 4. ed. Viçosa: UFV, 2011. 422 p.

NI-BIN, C.; PARVATHINATHAN, G.; BREEDEN, B. J. Combining GIS with fuzzy multicriteria decision-making for landfill siting in a fast-growing urban region. Journal Of Environmental Management, Kingsville, v. 87, n. 1, p.139-153, abr. 2008.

PMS, Prefeitura Municipal de Sorocaba. Plano municipal de gestão integrada de resíduos sólidos do município de Sorocaba - SP. Sorocaba: Prefeitura Municipal de Sorocaba, 2014. 
SALAMONI, R. H.; PINHEIRO, R. J. B.; NUMMER, A. V. Processo operacional da Central de Tratamento de Resíduos da Caturrita-Santa Maria, RS Operational process of Caturrita Central Residues Treatment Plant (CTRC)-Santa Maria, RS. Teoria e Prática na Engenharia Civil, n. 14, p. 43-50, 2009.

SALLES, M. H. D.; CONCEIÇÃO, F. T.; ANGELUCCI, V. A.; SIA, R.; PEDRAZZI, F. J. M.; CARRA, T. A.; MONTEIRO, G.; SARDINHA, D.S.; NAVARRO, G. R. B. Avaliação simplificada de impactos ambientais na Bacia do Alto Sorocaba (SP). Revista de Estudos Ambientais, Sorocaba, v. 10, n. 1, p.6-20, 2008.

SEARA, A. K. T.; GONÇALVES, M. A.; AMEDOMAR, A. D. A destinação final dos resíduos sólidos urbanos: alternativas para a cidade de São Paulo através de casos de sucesso. Future Studies Research Journal: Trends and Strategies, v. 5, n. 1, p. 96-129, 2013.

SNIS - Sistema Nacional de Informações sobre Saneamento. Relatório Anual da gestão dos resíduos sólidos no Brasil, ano base 2012. 2013. Disponível em: $<$ http://www.snis.gov.br/PaginaCarrega.php?EWRErterter TERTer=16> acesso em 03/06/2014.

SNSA - Secretaria Nacional de Saneamento Ambiental. Gasto Público em Saneamento Básico: Relatório de aplicações de 2008. Brasília - DF. p. 27-43. 2009. 